Andrey VARLAMOV ${ }^{1}$

Zheng $\mathrm{ZHOU}^{2}$

Yan $\mathrm{CHEN}^{3}$

\title{
BOILING, STEAMING OR RINSING? (THE PHYSICS OF CHINESE CUISINE)
}

\begin{abstract}
Some physical aspects of Chinese cuisine are discussed. We start from the cultural and historical particularities of Chinese cuisine and their food production technologies. What is the difference between raw and boiled meat? What is the difference in the physical processes of heat transfer during either the steaming of dumplings or during cooking them in boiling water? Why is it possible to cook meat stripes in a "hot pot" in ten seconds, whilst baking a turkey requires several hours? This article is devoted to a discussion of these questions.
\end{abstract}

Keywords: complex organic molecules, proteins, damplings, heat transfer, temperature conductivity, Fourier law, Newton's law of cooling

Globalization, which is rapidly taking place throughout the world, is vividly manifested by the ubiquitous availability of dishes of various cuisines from all over the world. Of course, as a rule, these have only some semblance of the true masterpieces of culinary art: in addition to the skill of the cook, the creation of the latter requires the corresponding products. As our familiar Italian gastronomic critic, Sergio Grasso, says, "food does not go to a person, this person should travel to food."

Chinese cuisine is one of the richest and most interesting cuisines in the world. Here everything, or, well, almost everything, can be eaten. And the ways of cooking are very different. One of the authors (AV) had a chance during a visit to Shanghai to open a small door into this wide world and, under the guidance of the two other authors, make some first steps in it, being interested not only in the exotic tastes but also in the underlying unusual physical processes.

Speaking about Chinese cuisine, the first things that come to mind, probably, are the dumplings, worldwide the most popular Chinese dish, which you can eat in Chicago, Canberra, or Moscow. Dumplings are honoured all over China, especially in Jiangnan region of China (close to the Yangtzi Delta). Three types of dumplings are commonly seen, especially in Shanghai and Suzhou, namely,

1 Andrey Varlamov, CNR-SPIN, Viale del Politecnico 1, I-00133 Rome, Italy

2 Zheng Zhou, Department of Physics, Fudan University, Shanghai, China

3 Yan Chen, Department of Physics, Fudan University, Shanghai, China 
Siaulon Pau, Santsie Moedeu and Wonton. Made of a thin dough, filled with pork, the fat of which melts into the soup when cooked, and served with Chinkiang vinegar, they are all pretty much the same. The most significant difference is the method of their heat treatment. Santsie Moedeu (large size dumpings) are panfried, this process is called in Shanghai "Santsie". Wonton dumplings are boiled in $100^{\circ} \mathrm{C}$, whereas Siaulon dumplings are processed also at $100^{\circ} \mathrm{C}$, but in an atmosphere of saturated steam in small bamboo steaming baskets which are called "Siaulon" (see Fig. 1).
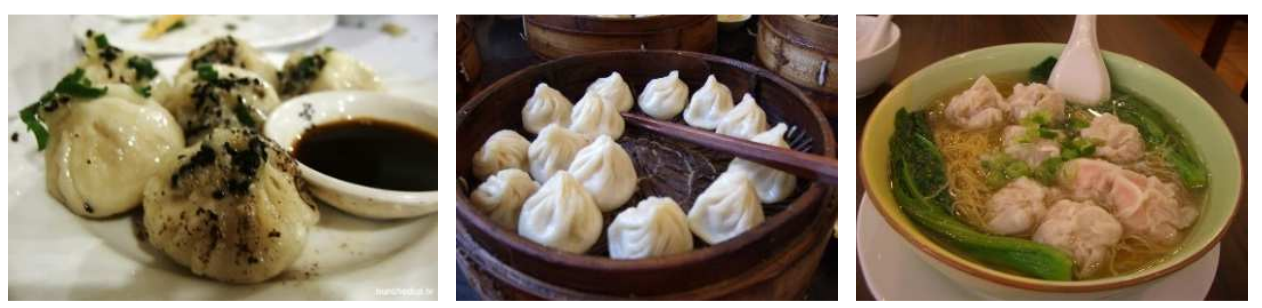

Fig. 1. The three kinds of dumplings in Jiangnan, China. The left one is Santsie Moedeu, the middle one is Siaulon Pau and the right one is Wonton

Hotpot is also a popular type of Chinese cuisine. Originating in Mongolia more than 1,000 years ago and gaining its popularity in the times of the Qing Dynasty $^{4}$ all over the country, hotpot boasts a profound history. During its spread, hotpot was diversified into many variations. Beijing hotpot lays particular emphasis on the soup base and sauces, Chongqing hotpot boasts a stimulating and refreshing “Ma La” (“麻辣”, “numb and spicy”) flavor, and Chaoshan hotpot is famous for its deliberately-prepared thin-cut mutton, named "Shuan Yangrou" (“涮羊肉”) in Chinese.

When enjoying hotpot, one puts ingredients such as beef balls, fish balls, crab meat, or vegetable slices into the elaborately prepared soup base and waits for it to be done. After picking it up and dipping it in the sauce, delicious food is ready to eat. The whole process is called "Zhu” (“煮”, “to boil”) in Chinese, and takes 5-10 minutes or so, when applied to meat balls or vegetables. Remarkably, in the meantime, another process can be used to get a different kind of food in the same hotpot, but much quicker. In Chinese it is called “Shuan” (“涮”, “rinse” or "instant-boil"). It consists of soaking the thin-cut sliced beef or mutton in the boiling soup. Surprisingly in only 10 seconds the sliced beef changes it colour

4 The Qing dynasty was the last imperial dynasty of China, established in 1636 and ruling China from 1644 to 1912 with a brief, abortive restoration in 1917. It was preceded by the Ming dynasty and succeeded by the Republic of China. 
from pink to white or gray, indicating that the slice is ready to eat. The beef slice becomes ready even without being let go of by the chopsticks (see Fig. 2).

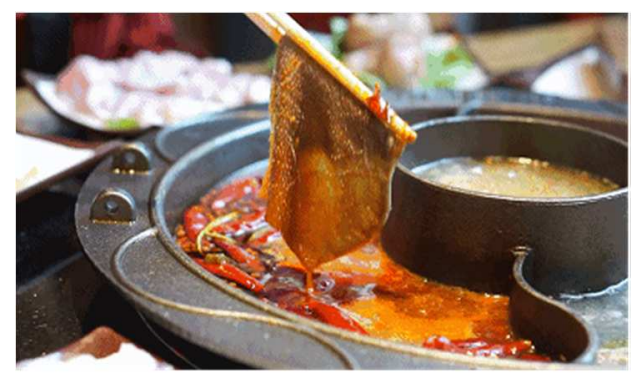

Fig. 2. Cooking in the hotpot

Today, cooking has become not only a giant industry, not only an art, but also a vast field of science. Here, biology, chemistry, physics, economics, ethics and many more intersect. The tasks of this science are infinite. All the time, new methods of cooking appear. We will not even try to list them here - neither those for the frying of meat, nor those for baking turkey, nor even the preparation of a BBQ on charcoal, none of them will be discussed here. Instead let's talk about the physical processes underlying cooking in the examples of the dishes described above - about the physics of boiling, steaming, and "rinsing in hotpot".

\section{Boiling}

What is the essence of the process of boiling meat? In everyday language, raw meat should become cooked. And what does this mean "scientifically"?

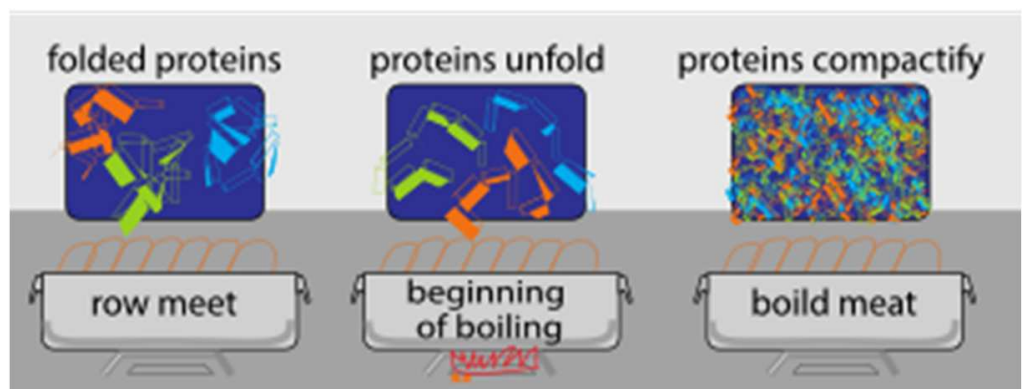

Fig. 3. Protein denaturation

Meat, basically, consists of complex organic macromolecules called proteins (the type of protein varies depending on the type of meat). In raw meat, the protein molecules are in a state of long entangled chains (Fig. 3). In the course of heat treatment, the temperature rises and these chains straighten, and when the tem- 
perature reaches value $T_{d}$, specific for each type of meat, they are compactified into a kind of "carpet". This process is called protein denaturation. It occurs at relatively low temperatures: for meat it is $55 \sim 80^{\circ} \mathrm{C}$, and for fish the temperature is even lower. In any case, anyone who has ever eaten a chicken soup can be sure that boiling it at $100^{\circ} \mathrm{C}$ turns out to be sufficient for completely compacting the proteins in the meat.

From the point of view of physics, the states of proteins in raw meat and boiled meat differ in their energy.

To turn the protein from its native state to the denaturated one, an energy barrier must be overcome (Fig. 4). At room temperature, this barrier is high. In the process of cooking, the temperature rises. Correspondingly the energy of the protein changes, as is shown in Fig. 4. Having reached the top of the "hill", the protein falls down to the new state - a denatured protein - the meat is cooked! This is what happens in a pot of boiling soup..$^{5}$
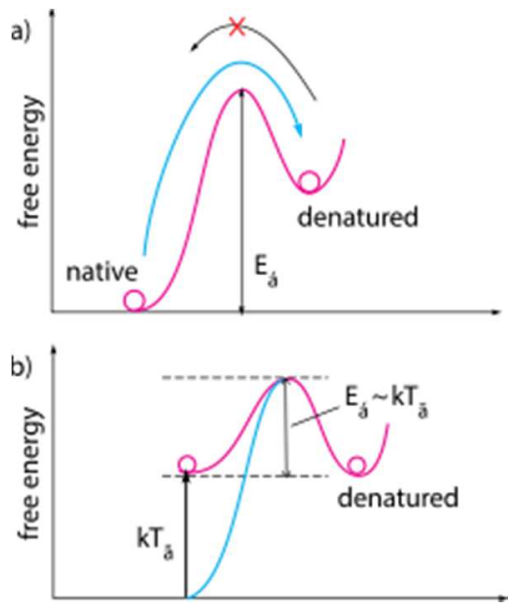

Fig. 4. A schematic presentation of the process how protein overcomes the energy barrier when the temperature increases

So, the first task of the cook when boiling meat in terms of physics is to increase the temperature throughout the volume of the piece to at least the temperature of denaturation.

\footnotetext{
5 It should be noted that in recent years became fashionable to cook meat at relatively low temperatures, the so-called "sous-vide" method. The meat is placed in a thermostat with a temperature somewhat lower than that of denaturation. Each separate macromolecule lack energy alone to jump over the barrier. However, it can occasionally "borrow" it from the environment. So, gradually (it takes a long time - many hours, maybe even a day), all bulk of the meat transfers into the denaturated state.
} 


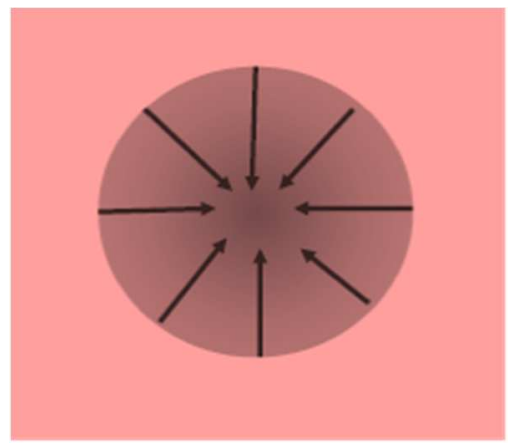

Fig. 5. Penetration of heat in the spherically symmetrical piece of meat

In the light of the above, we formulate the simplest model of the process of meat cooking. Let a spherically symmetric homogeneous piece of meat (radius $R$ ) with an initial temperature $T_{0}$ and a thermal conductivity coefficient $\kappa$ be placed in an environment where a fixed temperature $T_{e}$ is maintained. How much time does it take for the temperature of the meat in the center of the ball to reach $T_{g}$ ? (Fig. 5)

In mathematical physics, the process of heat transfer inside a sphere is described by a complicated differential equation [1]

$$
\frac{\partial T(r, t)}{\partial t}=\frac{\kappa}{\rho c} \frac{\partial}{\partial r}\left(r^{2} \frac{\partial T(r, t)}{\partial r}\right)
$$

where $T(r, t)$ is the temperature at a point $r$ at time $t, \kappa$ is the thermal conductivity of the meat, $\rho$ is its density, and $c$ is the specific heat. Since the water is boiling in a saucepan, the temperature at the surface of the sphere at any instant of time remains constant and equal to $100^{\circ} \mathrm{C}$

$$
T(r=R, \forall t)=100^{\circ} \mathrm{C}
$$

We took the meat from the refrigerator, so at the time when it was dropped into the water, the temperature was $4^{\circ} \mathrm{C}$ throughout its volume:

$$
T(\forall r, t=0)=4^{\circ} \mathrm{C}
$$

Equations (1)-(3) determine the problem of a differential equation with boundary conditions. How to deal with them is well known for mathematicians, and knowing the numerical values of the thermal conductivity of meat, its density and specific heat, they will be able to accurately write a recipe for cooking broth. 
Nevertheless, let's try to figure out the answer by ourselves using the method of dimensional analysis. The temperature of denaturation of meat is the same order of magnitude as the boiling point of water (it differs from it by only 20 25\%). Therefore, we assume that the time of "delivery" of the necessary temperature to the center of the solid sphere depends only on its material parameters: the thermal conductivity of the meat, its density, specific heat and radius. Therefore, we seek the dependence of the required time on the size of the sphere in the form:

$$
\tau=\kappa^{\alpha} \rho^{\beta} \mathrm{c}^{\gamma} R^{\hat{\delta}}
$$

By comparing dimensions, we write:

$$
[\tau]=[\kappa]^{\alpha}[\rho]^{\beta}[c]^{\gamma}[R]^{\delta}
$$

The dimension of the thermal conductivity is $[\kappa]=(\mathbf{k g} \cdot \mathbf{m}) /\left(s^{3} \cdot{ }^{\circ} \mathrm{C}\right)$. Substituting this and the dimensions of all the other physical values into equation (5), and then comparing them on the right and left hand side, we find: $\alpha=\mathbf{- 1}$, $\beta=\gamma=1, \delta=2$. Thus, we conclude that

$$
\tau=C_{0} \frac{\rho \mathrm{c}}{\kappa} R^{2}
$$

Where $\mathbf{C}_{0}$ is an unknown constant of the order of unity. Substituting the quantities $\kappa=0.45 \mathrm{~W} /\left(\mathrm{m} \cdot{ }^{\circ} \mathrm{C}\right), \rho=1.1 \times 10^{\mathrm{a}} \mathrm{kg} / \mathrm{m}^{3}, c=2.8 \mathrm{~kJ} /\left(\mathbf{k g} \cdot{ }^{\circ} \mathrm{C}\right)$, we find that for the meat $\chi=\kappa / \rho \mathrm{c}=1.5 \times 10^{-7} \mathrm{~m}^{2} / \mathrm{s}$. This value is called the coefficient of temperature conductivity. Consequently, a half kilogram piece of meat should be cooked for about an hour and a half. The estimate is in some way exaggerated, since we do not distinguish here the temperature of denaturation from the boiling point of water, but the order of magnitude is correct.

Returning to the dumpling whose diameter is about $2 \mathrm{~cm}$, we find that it should be cooked for several minutes, which corresponds to our life experience.

\section{Steaming}

Now let's discuss the physical aspects of the preparation of Siaulon dumplings. Here, a meat ball of radius $\mathrm{R}$ (our model of the dumpling) is placed into an atmosphere of saturated steam at $100^{\circ} \mathrm{C}$. The pressure here is atmospheric pressure, i.e. equal to $1 \mathrm{~atm}$. Formally, the Siaulon dumpling can be considered here as under the same boundary conditions as the wonton dumpling in the boiling water. Indeed, it is taken from the same refrigerator and is placed into an environment with a temperature of $100^{\circ} \mathrm{C}$. Therefore, from the point of view of 
a mathematician, the propagation of heat in the Siaulon dumpling is described by the same equation (1) with the boundary conditions (2) and (3). Therefore, if condition (2) is satisfied, then the temperature distribution inside it will be the same as for the wonton dumpling of the same size, and its preparation should take about the same time. However, a physicist is obliged to answer: how is one to ensure a temperature of $100^{\circ} \mathrm{C}$ on the surface of the Siaulon dumpling?

In the case of a "wonton" this was easy: even though immediately after its placement in the pan the boiling around it temporarily terminates. Due to the high heat capacity of the water, its good heat conductivity, convection, and the constantly supplied heat to the pan, the water will very quickly boil again thus providing condition (2) and hence, the required heat flow into the dumpling.

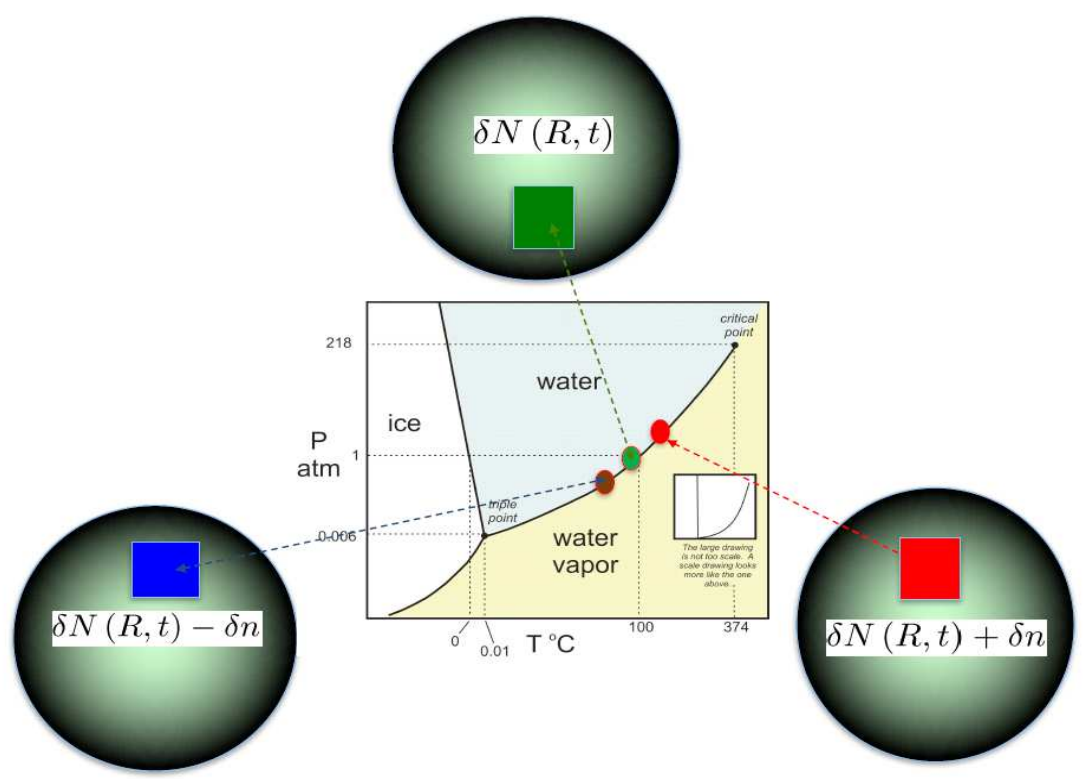

Fig. 6. A schematic representation of the process of dumpling steaming in the phase diagram of water. The environment ensures not only the heat flow but also the negative feedback suppressing its fluctuations

In the case of the "Siaulon", cooked in an atmosphere of saturated steam, the mechanism of the heat transfer into the dumpling is not so evident. How in this case is the boundary condition (2) ensured. Here the heat transfer has a completely different character from the one discussed in the previous section. At the first moment, the vapor molecules near the still cold surface of the "Siaulon" are locally in the state of a strongly supersaturated vapor. They begin to condense on the surface rapidly increasing its temperature up to the ambient temperature, $100^{\circ} \mathrm{C}$ (Fig. 6). Assuming that the temperature jump occurs in a very narrow region close 
to the surface, we return to the same equation (1) with boundary conditions (2) and (3). I.e., the temperature distribution inside the "Siaulon" should change with time in the same way as in the case of the "Wonton" boiled in the water. Consequently, the heat flux ${ }^{6}$

$$
q(R, t)=-\kappa\left[\frac{\partial T(r, t)}{\partial r}\right]_{r=R}
$$

at its surface should be the same. Yet, now this flow is provided not by the thermal conductivity of the water, but by the molecules of the vapor "landing" on $1 \mathrm{~cm}^{2}$ of the surface during 1 second:

$$
q(R, t)=\Gamma m(t)=\Gamma \frac{\mu_{\mathrm{H}_{2} \mathrm{O}}}{N_{A}} N(t) .
$$

Here $\Gamma$ is the specific heat of evaporation, $N(t)$ is the number of molecules condensed per second, $m(t)$ is their mass, $N_{A}$ is the Avogadro number, ${ }_{\mathrm{H}_{2} 0}$ is the molecular mass of water. Thus, the number of molecules "landing" from the steam atmosphere on a square centimeter of "Siaulon" per second is

$$
N(t)=N_{A} \frac{\kappa}{\Gamma \cdot \mu_{H_{2} O}}\left[\frac{\partial T(r, t)}{\partial r}\right]_{r=R}
$$

Perfect! Mathematicians can find this number by solving the complicated equation, the "Siaulon" itself "feels" what heat flux it needs to keep the temperature at $100^{\circ} \mathrm{C}$ on the surface ... It remains only to understand from where the molecules of the vapor learn how many of them should condense in a given second at a square centimeter of the "Siaulon" surface.

Let's suppose that at some time $N(t)+\delta N$ instead of $N(t)$ molecules condense. The first $N(t)$ of them are hospitably absorbed by the "Siaulon" - in fact, they are necessary to keep in harmony a centigrade surface and still a cold inner part. The remaining $\delta \mathrm{N}$ are persons "non grata" - they were not expected here, the temperature conductivity of the "Siaulon" does not allow their heat released

\footnotetext{
${ }^{6} \mathrm{~A}$ basic way for heat to enter the substance is thermal conduction [2,3]. When two objects with different temperature are in contact, heat flows from the one with high temperature to the one with low temperature. A basic model to study thermal conductivity is a slab of material of thickness.

The rate of thermal conduction is measured by the heat flux density, which is the amount of heat 睸_㔭_穄_穆_糜_窒_窒_窔_

Experimentally, and inversely proportional to the length. The coefficient is written in the gradient. The equation above is called "Fourier's law".
} 
to penetrate into the dumpling. What do they have to do? To take off again? Too troublesome, so they stay on the surface locally increasing its temperature (see Figure 6). As a consequence, the point that represents the local balance of the vapor and water moves up along their coexistence line. Let us notice that the pressure in the system remains the same, equal to $1 \mathrm{~atm}$. Therefore, above the selected square centimeter, the vapor locally ceases to be saturated. As a result, the next moment there will land somewhat fewer molecules than the required amount. Consequently, the surface temperature will go down.

Exactly the same mechanism works also in the case of that fewer than the required number of molecules condense onto the surface per second than would return the temperature back to $100^{\circ} \mathrm{C}$ (see Fig. 7). Such a mechanism of self-regulation is called negative feedback.

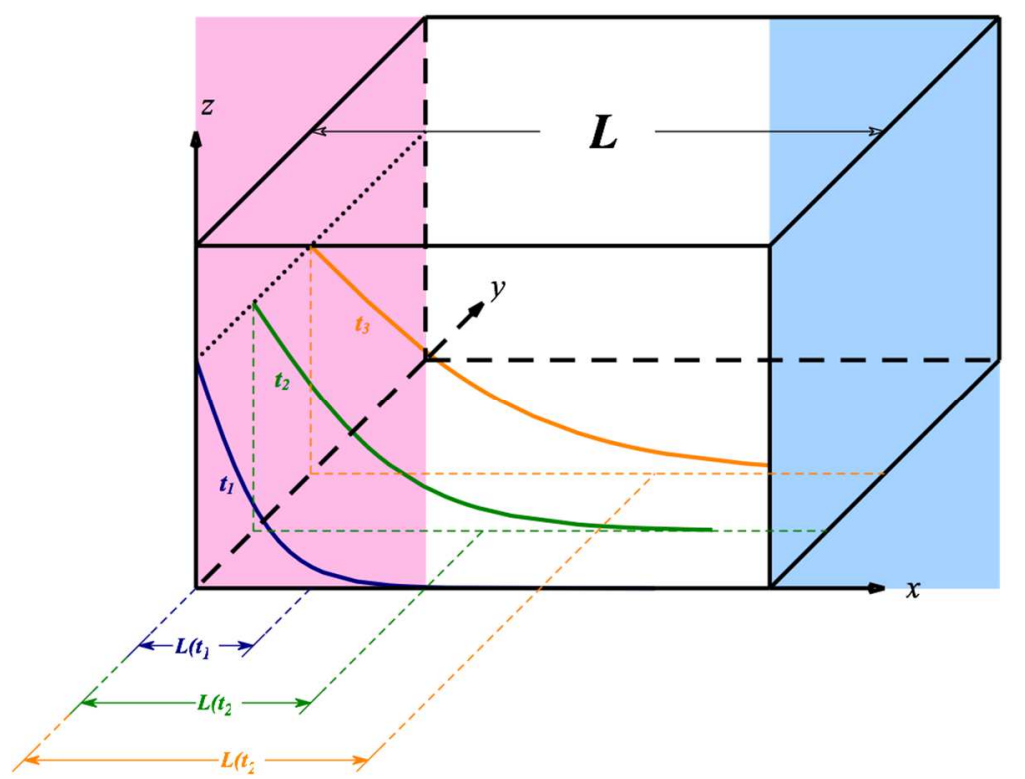

Fig. 7. A schematic of temperature penetration into a semi-space

Let us note the important culinary difference between boiling and steaming of dumplings. In the former case water penetrates into a dumpling due to the diffusion process. Interacting with its filling it creates a tasty juice. Due to the same diffusion, but in the opposite direction, this juice partially flows out from the dumpling to the surrounding liquid, transforming the water into a diluted broth. In the case of steaming the dumplings the ambient environment is the saturated steam. Once condensed at the surface of a dumpling the water also diffuses into its bulk, but there is no inverse process. Hence, the juice of the steamed dumpling is richer than that of the boiled dumpling. 


\section{Rinsing}

At the beginning of this article we discussed the "hot pot" and the different ways of cooking meat in it. Yet there still remains the mystery as to why the same amount of meat in the form of a meatball or a thin slice differs in its cooking time by up to ten times. Why the oil soup base "Hongyou" in the Chongqing pot boils much earlier than the water soup "Qingtang" used in its Chaoshan and Beijing versions? We will try to answer these questions below.

\section{On cooking times}

"Shuan" and "Zhu" is actually the same thermal process which was discussed in the previous sections. Here heat conductivity and convection provide a constant temperature $100^{\circ} \mathrm{C}$ on the surface of the object and heat enters inside it, raising the internal temperature. So, what causes this striking difference in time between rinsing the thin-cut beef and boiling the meatball? The answer requires an inspection of the thermal process of boiling.

With the time of "Zhu" everything is clear: the way of heat propagation in the ball, which can serve as a meatball model, we already discussed (cooking of the Wonton dumpling), and we can use Eq. (6) to estimate the corresponding time. The cooking time of the "Shuan" process requires separate consideration.

We consider a body occupying the semi-space $x>\mathbf{0}$ (see Fig. 7) We assume its density, heat capacity, and heat conductivity to be $\rho, c, \kappa$, and with a temperature $\mathbf{T}_{0}$ at the initial moment $t=\mathbf{0}$. Now let us change the temperature at its surface $x=\mathbf{0}$ to $\mathbf{T}_{\mathbf{1}}$ and fix it. Fig. 7 shows how the temperature evolves with time in the bulk of the body. We can see that heat penetrates into the medium little by little. One can introduce characteristic length $L(t)$ to describe the propagation of the temperature front with time. Returning to Fourier law (see Eq. (9)) and replacing the thickness $\Delta x$ by the characteristic length $L(t)$, substituting $Q=m c \Delta T$, and $m=\rho A L(t)$, one finds

$$
\frac{c \rho A L(t) \Delta T}{A t}=\kappa \frac{\Delta T}{L(t)}
$$

Solving this equation with respect to $L(t)$

$$
L(t) \sim \sqrt{\frac{\kappa t}{c \rho}}=\sqrt{\chi t} .
$$

Solution of the exact differential equation describing the process confirms our qualitative consideration [4] and gives an extra $\sqrt{\pi}$ coefficient in (10): 


$$
L(t)=\sqrt{\pi \chi t}
$$

Hence, we found that heat penetrates into the medium by the square-root law of time, the parameter $\chi={ }^{\kappa} / c \rho$ is called the thermal diffusivity or coefficient of temperature conductivity ${ }^{7}$. The time of the establishment of the temperature $\mathbf{T}_{\mathbf{1}}$ in the slab of the thickness $L$ can then be evaluated as $\tau \sim L^{2} / \pi \chi$

Now we can return to a comparison between the rinsing time of a thin-cut beef versus the boiling time of a meatball. We consider an $a \times b$ rectangular slice of thickness $d$ and a meatball of radius $R$ out of the same volume of meat.

During the boiling process, temperature should penetrate into specimen up to the farthest point from the surface. Thus, the required length for thin-cut slices and meat balls are respectively half its thickness and its radius. The times for them to be done are

$$
\tau_{\text {slice }} \sim \frac{(d / 2)^{2}}{\pi \chi} \quad \tau_{\text {ball }} \sim \frac{R^{2}}{\pi \chi}
$$

The ratio between their cooking times is

$$
\frac{\tau_{\text {ball }}}{\tau_{\text {slice }}} \sim\left(\frac{2 R}{d}\right)^{2}
$$

The size of a thin-cut sliced beef in China typically is $a \times b=3 \times 15 \mathrm{~cm}$ and its thickness is $1 \mathrm{~mm}$, which is marvelously thin. Out of the same volume of beef, using $a b d=4 \pi R^{3} / 3$, we can make a beef ball whose radius is $R=1.0 \mathrm{~cm}$ . The ratio $2 R / d=20$ and the estimated difference in cooking times is

$$
\left(\frac{\tau_{\text {ball }}}{\tau_{\text {slice }}}\right)_{\text {est. }} \sim 400
$$

Stop! As we have mentioned above the common times for the ball and the slice to be cooked are 5 minutes and 10 seconds, i.e. the realistic value for the ratio is

7 Thermal diffusivity is a physical quantity that describes the rate of change (align) the temperature of the substance in a non-equilibrium thermal processes. 


$$
\left(\frac{\tau_{\text {ball }}}{\tau_{\text {slice }}}\right)_{\text {real. }} \sim 30
$$

This number differs by an order of magnitude with (11), this is too much. The reason for this discrepancy is our assumption that all of the cooking time is spent on "delivery" of the necessary temperature through the whole volume of the meat. However, we ignored the time required for carrying out the denaturation process itself. In most cases, this time, $\tau_{\text {denat. }}$, is so short that it can be neglected with respect to the "delivery" time. Yet, the "Shuan" process is so quick that the denaturation time cannot be neglected and has to be added to

$$
\tau_{\text {slice }} \tau_{\text {slice }}^{\prime}=\tau_{\text {denat }}+\frac{(d / 2)^{2}}{\pi \chi}
$$

where the temperature conductivity of the beef is taken as $\chi_{\text {beef }}=1.5 \times 10^{-7} \mathrm{~m}^{2} \mathrm{~s}^{-1}$. The value of the second term in (14) is only $\left.\left(\frac{1}{2}\right)^{2}\right)^{2} /$

$\chi^{\sim 0.5 \mathrm{~s}}$, while one rinses it in the hotpot around 10 seconds. It is why we conclude that all this time is required for the chemical reaction of denaturation i.e. $\tau_{\text {denat }} \sim \mathbf{1 0 s}$. Of course, this value is negligibly small compared with that required to increase the temperature throughout the entire meatball volume above the denaturation point, but it turns out to be dominant when rinsing a slice of meat in a hot pot. The new estimate $\tau_{\text {slice }} \sim \mathbf{1 0 s} \tau_{\text {ball }} \sim \mathbf{2 2 0} s$ agrees well with Chinese experience.

Table 1. Comparison among three ways of cooking mentioned above - boiling, steaming and rinsing

\begin{tabular}{|l|lll|}
\hline \multicolumn{1}{|c}{} & \multicolumn{1}{c}{ Boiling } & \multicolumn{1}{c|}{ Steaming } & \multicolumn{1}{c|}{ Rinsing } \\
\hline Size & Radius $R$ & Radius $R$ & Thickness $L \ll a, b$ \\
\hline Cooking time & $\tau \sim \mathbf{R}^{2} / \pi \chi$ & $\tau \sim \mathbf{R}^{2} / \pi \chi$ & $\tau \sim \mathrm{L}^{2} / \pi \chi$ \\
\hline $\begin{array}{l}\text { The Way } \\
\text { of heat transfer }\end{array}$ & $\begin{array}{l}\text { Thermal conductivity } \\
\& \text { natural convection }\end{array}$ & $\begin{array}{l}\text { Latent heat of the con- } \\
\text { densing steam }\end{array}$ & $\begin{array}{l}\text { Thermal conductivity } \\
\text { \& forced convection }\end{array}$ \\
\hline Environment & $\begin{array}{l}\text { Boiling water/diluted } \\
\text { broth }\end{array}$ & Saturated steam & Boiling soup-base \\
\hline
\end{tabular}




\section{On soup bases}

Besides the process of boiling sliced beef itself, the soup-base also contains some physics in it. First of all, it differs strongly from the diluted aquatic broth formed during the boiling of dumplings(see above). The soup-base for the hot pot is prepared in advance, mixing water with oil and other ingredients. Below we discuss some of its specific properties which also have interesting physical reasons.

"Qingtang" soup base is commonly used in the Beijing and Chaoshan hotpots. It constitutes a mix of water with a small amount of oil, salt and other condiments. Contrarily, for cooking in a Chongqing hotpot the "Hongyou" (spicy oil) soup base serves. A large fraction of "Hongyou" soup is oil stewed with chili powder, Chinese prickly ash, etc. The remaining part is a small portion of water. If one starts to heat both soups simultaneously, the oil soup-base will start to boil much earlier than the water soup. It seems to be rather strange, since the boiling point of oil (if any) is much higher than that of water. Actually, what boils here is not the oil, but the small portion of water in the soup. Hence, the Hong You soup starts to boil at the boiling point of water instead of that one of oil.

There are two reasons which explain why the "Hongyou" soup needs a shorter time to boil.

The first is that the specific heat capacities of oil and water are respectively $c_{\text {oil }}=2 \times 10^{3} \mathrm{~J} /\left(\mathrm{kg} \cdot{ }^{\circ} \mathrm{C}\right)$ and $c_{\text {water }}=4.2 \times 10^{3} \mathrm{~J} /\left(\mathrm{kg} \cdot{ }^{\circ} \mathrm{C}\right)$, so that less than half the heat is needed to raise the temperature of the oil soup base from room temperature to $100^{\circ} \mathrm{C}$.

The second reason concerns heat dissipation. The process of the heat dissipation is due to both heat conduction and convection processes. In the latter energy is transferred by the movement of a heated substance as a result of differences in densities of lower and higher layers.

The heat flux at the surface is loosely described by Newton's law of cooling, which claims that the latter is proportional to the temperature difference: $q=h \Delta T$.

The coefficient $\boldsymbol{h}$ is called the heat transfer coefficient and describes how violent the convection is. The typical values of the heat transfer coefficient for boiling water and oil are respectively $2.5 \times 10^{3} \sim 25 \times 10^{3}$ and $0.05 \times 10^{2} \sim 1.5 \times 10^{2}$, in units of $\mathbf{W} \cdot \mathrm{m}^{-2} \mathrm{~K}^{-1}$. The significant difference in $\boldsymbol{h}$ may be explained by the viscosity and the poor heat conductivity of oil. As a result, the heat dissipation at the interface between the oil soup and air is two orders of magnitude less than that in the case of water soup.

Manman Chi! ${ }^{8}$

8 慢慢吃-“eat slowly”, Chinese version of “enjoy your meal” 


\section{REFERENCES}

[1] Bergman T.L., Lavine A.S., Incropera F.P., DeWitt D.P., Introduction to Heat Transfer, 6th Edition, Wiley, 2011.

[2] Feynman R.P., Leighton R.B., Sands M., The Feynman Lectures on Physics, Vol. I: Mainly Mechanics, Radiation, and Heat, The New Millennium Edition, Basic Books, 2011.

[3] Reif F., Fundamentals of Statistical and Thermal Physics, Waveland Pr Inc, 2008.

[4] Unsworth J., Duarte F.J., Heat diffusion in a solid sphere and Fourier Theory, Am. J. Phys., 1979, Vol. 47, No. 11, pp. 891-893.

\section{GOTOWAĆ, GOTOWAĆ NA PARZE CZY MOŻE PŁUKAĆ? (FIZYKA KUCHNI CHIŃSKIEJ)}

W artykule zostały przedyskutowane niektóre aspekty kuchni chińskiej. Autorzy zaczynają od omówienia szczegółów kuchni chińskiej i technologii produkcji żywności. Autorzy zadają następujące pytania: jaka jest różnica pomiędzy mięsem surowym a gotowanym? Jaka jest różnica w fizyce procesu przenoszenia ciepła podczas przyrządzania klusków na parze wodnej a w gotującej się wodzie? Dla czego jest możliwe przyrządzanie kawałków mięsa w "gorącym garnku" w ciągu kilku sekund, podczas gdy po to, aby upiec indyka potrzebujemy kilku godzin? Artykuł ten udziela odpowiedzi na te i inne pytania.

Słowa kluczowe: złożone molekuły organiczne, proteiny, kluski, przenoszenie ciepła, przewodnictwo temperaturowe, prawo Fouriera, Newtonowskie prawo chłodzenia

DOI: 10.7862/rf.2018.pfe.5

Received 11.06.2018

Accepted 15.09.2018 